\title{
The Development and Personality of Engineers
}

\author{
LYNNETTE BEALL and EDWARD S. BORDIN
}

\begin{abstract}
An analysis of engineers and engineering making use of a scheme of the gratifications that work can offer and of theories of personality development. Using previous analyses of the activities of engineers and psychometric and interview studies, the following characteristics were found: (a) concentrates on material products and practical outcomes; (b) adopts a clear masculine role and exhibits a strong identification with authority; (c) prefers the planful, orderly, and objective; (d) through specialization finds travel and adventure, shows daring, satisfies mainly impersonal curiosities, augments his physical powers, and acts in manners derivative of the male role. Concerning developmental influences some support is found for: (a) his father and mother being clearly differentiated in sex role; (b) vigorous enforcement of clear-cut rules; (c) a close relationship between father and son; (d) an early emphasis on self-reliance and achievement.
\end{abstract}

N RECENT YEARS greater concern with personality factors in the choice of a vocation has been added to the earlier established attention to aptitudes, skills, and knowledge. Bordin, Nachmann, and Segal (1963), building on earlier work done by themselves and others, presented a schema of the gratifications that varieties of work can offer and traced these gratifications to the physiological functions necessary to their achievement. They looked to psychoanalytic theory as a major source of hypotheses regarding the kinds of early experiences that would channel energies into particular modes of obtaining gratifications.

A natural application of this line of thought lies in occupational analysis. This concern with the role of personality in vocational development leads to a purpose and style of analysis different from the tradi-

LYNNETTE BEALL is a member of the staff and EDWARD S. BoroIN is Chief, Counseling Division, Bureau of Psychological Services of the Institute for Human Adjustment, The University of Michigan, Ann Arbor. tional one which is focused on identifying general and specific aptitudes, as well as levels of education or training that performance of specific jobs or families of jobs requires. Direct observation of the worker on his job remains an important procedure. In the new approach, however, the observer aims to identify the modes of expressing and controlling one's impulses afforded the worker by the activities required or permitted. Another important source of evidence comes from indications of how the worker experiences his work. In the professions where articulate and introspective men are most likely to be found, diaries and autobiographies can be an important source of data. Public'speeches and personal interviews represent other sources for obtaining an understanding of how a given occupational group experiences its work.

This paper reports the results of such an analysis of the engineering occupations. This kind of study of occupational groups can serve two purposes. On the theoretical and research side, it can provide a basis for further verification of theories about the 
role that personality plays in vocational choice. Studies by Galinsky (1962) of clinical psychologists and physicists, by Nachmann (1960) of lawyers, social workers, and dentists, and by Segal (1961) of accountants and creative writers have already provided examples of this sort of occupational analysis and offered evidence from personality measures and reports of childhood experience that supports the theory that personality factors do play a role, albeit not the only one, in the choice of a vocation. Secondly, this type of study can alert vocational counselors to the likely sources of motivational conflict behind the decisional paralysis that some of their clients exhibit.

The schema developed by Bordin, et al. (1963), consisted of a vertical axis made up of the various physiologically based sources of gratification, those around the activities of the mouth, i.e, nurturant (feeding and fostering), and aggressive (cutting, biting, devouring); manipulative activities designed to exert physical and interpersonal power; sensual activities, not for information but for pleasure (seeing, touching, hearing) ; activities deriving from anal impulses, acquiring, timing-ordering, hoarding, and smearing; derivatives of phallic and genital impulses, erecting, penetrating, impregnating, and producing; exploratory activities, seeing, touching, and hearing; and finally the activities of flowing-quenching, exhibiting, and rhythmic movement. The vertical axis contains five different ways in which these activities may be expressed in different occupations. One aspect refers to the importance for the occupation of the particular type of activity. A second indicates the tools or activities through which the impulse is expressed. The range of possibilities is from the physical actions of the body to tools, words, abstract concepts, and symbols, e.g., the expression of oral aggressive impulses to cut or bite may take the form of words being used destructively as in an argument or debate. A third aspect deals with the objects or things toward which the activity is directed. The range of possibilities is from human beings or body parts to animals, plants, inanimate objects, and abstractions. A fourth aspect refers to whether the activity appears to be patterned after a masculine or feminine model. The final aspect deals with the effective component of the activity, whether it is accepted or repressed. It might include a specification of the particular mechanism of defense or mastery employed.

As further research clarifies the tenability of this proposed framework as a way of describing occupations and leads to modifications and additions to it, the vocational counselor can look forward to a chart in which the major occupations are mapped showing their significance as outlets for various personality needs.

\section{METHODOLOGICAL CONSIDERATIONS}

Instead of observing engineers at work, a project beyond our current resources, we turned to the reports of the activities of engineers contained in materials prepared for counselors and students (Angel, 1953; Engineering as a Career, 1942; Stewart, 1942; Guides to Planning an Education, 1961). It can be argued that one ought to gather new observations of engineers, conditioned by a set to look for personal significance. We are inclined to believe that the basic description of the activities in the occupation would remain unchanged. What is needed is an analysis of their personal meaning. Therefore, existing descriptive materials will adequately serve our purpose.

One of our most important sources of data was the analysis of biographies and autobiographies. From them we obtained evidence of the subjective experience of the occupation and suggestions as to the kind of developmental history that goes into the making of an engineer. In dealing with such materials one must be conscious of several sources of error. Those for whom biographies are written or who write autobiographies are likely to be more than engineers; they are eminent men. It is a difficult task to separate those forces which drive a man toward outstanding achievement from those that select engineering as one aspect of its expression. Another difficulty arises from the lag between the life of an engineer and the publication of his biography. Biographies are necessarily 
retrospective. In an era of explosive technological change, the demands, opportunities, and gratifications offered by the engineering profession (at the helm of this change) must be changing as are the personalities who seek to express their needs and find gratification in its work. The biographies of today's engineers are not yet on the book shelves, so we must be satisfied with yesterday's. Finally, there is the question of whether there is an engineer or varieties of engineers, each so different that any generalized description is meaningless. We take the midway position that engineers of all varieties share a significant base of activities and, further, that the varieties of sub-categories can be meaningfully grouped according to content or function.

Finally, we have made use of what relevant research is available on the personality characteristics which distinguish engineers from other occupational groups and differentiate among types of engineers.

We shall begin with an analysis of the basic characteristics of engineering that emerge from the descriptions of the activities of engineers. Following this, we will examine the degree to which research supports this anaylsis and the kinds of support found in biographies. Then we will turn to the questions of the kinds of experience that fashion the engineer, relying primarily on evidence from biographies.

\section{BASIC CHARACTERISTICS OF ENGINEERING}

Every description of the engineer gives central importance to his role as a producer. Sometimes, as in the case of the mining or petroleum engineer, he plays a hand in the procurement of the raw materials, but the salient function of the engineer is applying physical laws and knowledge of the mechanical properties of materials to the production of goods. He might be said to use the intangible and the abstract to provide for man's tangible and material needs. These products range from the immensely scaled and highly visible large skyscraper or bridge to minute constituent parts of machines or electrical communication systems. Directly or indirectly, the engineer is involved with action and power.
Civil and mining engineers often work in the field where direct physical demands must be met. More typically engineers are involved in augmenting man's physical power via tools, machines, and releasing chemical and electrical energy. In this sense of being concerned with action, preparing for action, and with exerting physical power, the engineer typifies a masculine role.

The engineer's attachment to the masculine role is further emphasized in the description of the methods of the engineer as "orderly, dispassionate, and planful." The engineer works with the language of science, which is principally mathematics. While this language can be used imaginatively and creatively, its principal value for the engineer is the degree to which it provides precision in deriving practical uses of materials. Engineering provides an excellent outlet for the person who prefers to work with well-defined concepts and who is irritated or disturbed by open-ended or ambiguously specified terms. The engineer eschews the subjective and introspective modes of thought. He likes the feeling of dealing with issues in depersonalized terms. Passions and other interpersonal affects are disturbing and must give way to the systematic and the analytical. This suggests that isolation will be an important psychological mechanism for the engineer. Since, unlike the social scientist; he prefers to deal with the physical as compared to the world of human relations, repression rather than intellectualization will be paired with isolation.

Identification with authority, mainly male authority, would seem to be another salient feature. This flows first from the above-mentioned fact of the engineer's close identification with the masculine role and from his reliance on basic principles from which to derive specific uses of materials. To the extent to which he is not an innovator of principles, the engineer gains his understanding of science via his identification with a particular way of approaching the real world. There is another feature of engineering that underlines the engineer's identification with authority. 
Typically, the engineer works as part of an organization. The production of goods and materials involves an organization of men and machines. The engineer must necessarily identify with that organization. That he is usually well suited to such a function is indicated by the regularity with which engineers rise to the top layers of these organizations. The engineer's capacity to accept an authoritative role indicates that his is a successful identification in which he can confidently assume the mantle of his ruler.

\section{ENGINEERING SPECIALTIES}

We believe that the characteristics described above loom large in any form of engineering. Perhaps the great overlap among engineering curricula reflects this fact. There are two ways to subdivide engineering specializations; one is by the kinds of products and the other is by function. Curricula are usually classified by product, viz., civil engineers who produce various kinds of fixed structures, e.g., buildings, dams, roads, bridges; mechanical engineers, who construct machines; aeronautical, chemical, electrical, mining, and industrial engineers. Although studies suggest that the varieties of engineers can be grouped, that mechanical and aeronautical engineers are similar, that chemical and industrial engineers stand apart, and that sales engineers show patterns least like other engineering groups, there still remains a residue of characteristics specific to each specialty. Here our analysis has not been searching enough to offer more than a few observations. Both mining and civil engineering have the characteristics of making for geographic mobility. Of the two, mining gives somewhat greater emphasis to risk and exploration, including the inside of the earth, which might also reflect an opportunity to experience a form of penetration. Both mechanical and aeronautical engineers experience the augmenting of their own power through the designing and construction of machines, but the latter through his involvement with flight has an opportunity for investments in exploration, risk, and the use of great explosive power such as in propulsion and missiles. Chemical and industrial engineers are much concerned with processing, the former with materials and the latter with the interrelations of men and materials. Though the engineer in general has the tendency to reduce persons to formulas or equate their status to inanimate objects, it is an important part of the industrial engineer's task to fit persons into a working system with machines. Obviously persons are unique kinds of machines and the history of industrial engineering reflects increasing awareness of this fact with greater attention to the social sciences. One of the salient features of the task of the electrical engineer is that he deals with energy and power in a somewhat more abstract or more generalized form than other engineers. Thus, when it comes to practical applications, he must be informed in other fields of specialization. This apparent test of his ability to learn is reflected in suggestions that this group may be the most theoretically oriented of the varieties of engineers. Curiosity, which surely is a driving force in scientific discovery, can also be expressed by the electrical engineer via his involvement with electrical methods of communication. Then again his role of facilitating communications between persons could also reflect a deflected yearning to participate in closer human relationships.

Under the functional classification, the research engineer, who is most different from other engineers, is usually closest to the basic scientist. Thus, we expect greater emphasis on originality and curiosity, less identification with authority, and explorations centered in the sphere of abstractions. In developmental work, we find the more typical research function of the engineer, that of turning the results of basic research into a form that leads to new products or processes. In design, construction, operation, management, and sales engineering, we have a continuum of degree of closeness to the concrete product and then beyond it toward relations among persons, processes, and products, with sales engineering representing an emphasis on human relationships. 


\section{SUPPORTING EVIDENCE}

The masculinity of the engineer's interest pattern is already fairly well documented. Roe (1956, p. 160) presents the kind of evidence obtained from the Strong Vocational Interest Blank which shows engineers with one of the highest mean masculinity scores. In studies of activity patterns of engineers, Thorndike and Hagen (1959) find differences among the engineering specialties. While civil, electrical, and mechanical engineers are similar, chemical and industrial engineers stand apart, and sales engineers show a pattern least like the other engineering groups.

Mechanical, civil, and electrical engineers all show a common early interest in mechanical processes with civil engineers evidencing an early interest in tools and electrical engineers showing an early interest in radio.

Given the engineer's investment in masculinity and his emphasis upon physical power and augmenting it, we are drawn to the question of how his physical strength compares with that of representatives of other occupational groups. One source of data is Begelman's (195l) study of physique and physical performance of entering freshmen in various colleges. He found no systematic differences in physique, and engineers tend to fall in the middle in a series of seven physical performance tests. Since as an older adolescent the engineer cannot be described as markedly deviant in his physical powers, we would have to look elsewhere for an explanation of his concern.

Although few studies involve definitive research designs, their results tend to support the picture of the engineer as "orderly, dispassionate, and planful." Reporting on a study of 100 mechanical engineers via projective tests, personality inventories, and clinical interviews, Harrison, Tomblen, and Jackson (1955) describe engineers as having harmonious but casual interpersonal relations, rarely showing an analytical interest in people, avoiding introspection and selfexamination, being matter of fact, and, outside of their own field, often unimaginative, liking phenomena to be clearly structured, being straightforward, direct and self-suf- ficient, and as being energetic advocates of direct action.

Not so clear is the question of how conflict-free is the engineer's social life. The study cited above found mechanical engineers to be emotionally stable and to exhibit a normal amount of social participation. Kulberg and Owens (1960) working with much more superficial data report a history of painful and/or not completely successful personal-social contacts. Blum's (1947) study adds data which cannot be interpreted clearly. In comparing the Strong Vocational Interest Blank and the Minnesota Multiphasic Personality Inventory, he scored the former for group rather than individual scales. He found that Group II scores, which includes engineers, mathematicians, physicists, and chemists, correlated positively with depression and social introversion and that high scorers on Group II were highest on the Hysteria and Social Introversion scales and lowest on the Schizophrenia scale. Roe (1956), citing a study by Harrower and Cox (1942) which we were unable to examine, reports that physical science and engineering groups show somewhat compulsive, rigid, and anxious personality pictures. On the other hand, Mosier and Kuder (1949), basing their data on the Kuder Preference Record, found mechanical engineers to be well above the mean of an unselected group on a "conflictfree" dimension.

There are difficulties in drawing conclusions from these studies because they differ so widely in the levels of personality tapped, in the degree to which clear group comparisons are involved and in the representativeness of their samples of engineers. In the sense in which all of us must work out compromises in which certain gratifications are sought and others are avoided, all in the interest of a workable, reasonably stabilized equilibrium of gratification and anxiety reduction, engineers will show their characteristic compromise. But we do not expect that their compromise will be marked by any more definite pathology than any of the other occupations.

When we turn to the perceptions by engineers of their work as found in auto- 
biographies or in other personal papers, we find support for our description. These are reported under various relevant headings.

\section{Things Rather than People}

"I have not said anything of the passengers who cover the deck of the vessel. .." (Maxwell, 1886, p. 31). (After lengthy, tedious descriptions of all the objects and processes he had observed.)

After describing a job where the chief engineer promoted purely social gatherings which "inspired friendships," Ridgway (1940, p. 198) concludes that although he finds himself wishing that he could repeat these experiences he feels this a selfish thought and adds, "any human being should be satisfied with one such experience in life."

\section{Preference for the Practical and the Objective}

"I had no taste for it (the law) ... my interest was in doing something constructive dealing more directly with the forces of nature" (Ridgway, 1940, pp. 19-20).

"The quality of mind which probably embraces all forms of engineering is that of an infinite curiosity directed more particularly to happenings in the world we call matter. . . and the desire to be a builder or an operator" (W. H. Abbott, Electrical Engineer, in Drayer \& Newell, 1916, p. 67) .

"They (engineers) must apply the objective method of science to the things that directly affect their lives and material surroundings. . . without regard to inbred or subjective attitudes" (Mills, 1946, p. xviii) . The Power and Grandeur of the Natural Laws vs. the Whims of Personality

". . . there was no work which, as regards the grandeur and utility of its results, could compare with this" (de Lesseps, 1887, p. 173).

". . . his life is spent among the great things of nature ... the sublime grandeur of the natural forces and of their laws. . . are his constant companions. .." (A. J. Himes, Givil Engineer, in Drayer \& Newell, 1916 p. 95) .

\section{Collecting Facts by Careful Observation}

Robert L. Stevenson describes his father watching an oil-tube with watch and notebook in hand. . . "The fact acquired might never be of use; it was acquired" (Stevenson, 1912, p. 82).

To the engineer the waves on the beach provide a "checker board of lively forces"; to the artist (the son, author of Treasure Island) it was a "pretty and various spectacle" (Stevenson, 1912, p. 85).

"I am anxious to see all this for myself, as when $I$ have taken in a thing myself $I$ shall be able to make it comprehensible to those who are not engineers" (de Lesseps, 1887, p. 200). The feeling of power over others comes out quite strongly in this comment from the builder of the Suez Canal.

\section{Need for "Clean-Cut" Certainty}

"It was always a pleasure to read a communication (he) had prepared. His reports were clear and concise, and he had an excellent command of English. Like most forceful writers he preferred short words; his statements were direct and with only one meaning" (Ridgway, 1940, p. 254).

"The very term mensuration sounds 'engineer-like'. . . in truth what the engineer most properly deals with is that which can be measured, weighed, and numbered ... these are his conquests. . . these are the certainties of the engineer. . " (Stevenson, 1912, pp. 82-83).

"I long to get into a house again. Though tents are extremely comfortable, there is no way of keeping things tidy-there are no clothes-rails nor cupboards. . ." (Maxwell, 1886, p. 22).

\section{Masculine Adventure and Daring}

“. . . looking upwards at the part of the railway on which the train had been a minute before, made one feel that there was wonderful daring in the man who first made the common road. .." (Maxwell, 1886, p. $6)$.

"On steep parts of the railway, the central wheels grip the central rail laterally, and as it were, climb up by it, as a boy would climb a tree" (Maxwell, 1886, p. 6). (Even in this observation-a simile of masculine adventure.)

Among the gratifications that engineering offers, Drayer and Newell include these defi- 
nitely masculine preferences: "having the upper hand," "love of the sea, of adventure" and the "challenge of unsolved problems."

\section{THE MAKING OF AN ENGINEER}

What kinds of early experiences focus a man's attention on the production of objects and materials? What facilitates the development of a close and successful identification with male authority? How is it that the engineer becomes so engrossed in augmenting his physical powers? What makes an engineer so intent on proceeding so systematically, so planfully, and so dispassionately? These are the questions that must be answered in order to understand the influence of his experiences while growing up on the engineer's commitment to his vocation.

\section{INVOLVEMENT WITH PRODUCTS AND THE PRACTICAL}

The basic human investment in other persons as objects of the expression of love and the search for intimacy is further accentuated in infants and young children by their dependence on others' care. At the same time, basic investments in mastery and self-assertion as well as curiosity turn attention to the material world. Other things being equal, one might expect that all persons would develop a balance of investments in people, objects, and ideas. But we have seen that in the engineer we find an over-developed interest in material objects and a corresponding under-investment in persons. We might speculate, then, that the engineer will have experienced an upbringing in which relatively early demands were made to take care of himself. Obviously, these could not be harsh and completely unloving demands for self-reliance, but perhaps coupled with a tendency for both parents to be on the undemonstrative side.

\section{IDENTIFIGATION WITH MALE AUTHORITY}

Relatively early the child becomes aware of the physical and psycho-social differences between the sexes. How clearly these differences are perceived and built into his own sexual identity is a function of the kinds of models offered by his mother and father and by the vicissitudes of the resolu. tion of the oedipal conflict. Engineers pattern themselves so clearly into the social definition of the male role that one must conclude that their mothers and fathers must have enacted very clearly their respective socially defined sex roles.

Psychoanalytic theory suggests that the inevitable first libidinal attachment to the mother brings the young boy into potential rivalry with his father. Since boys need fathers as well as mothers, this competition is a doubly threatening one, which the father's affectionate companionship aids in resolving. With such a companionable father, it becomes easier and more meaningful for the boy to renounce competition and, instead, to set out to emulate his father by acquiring those characteristics that his mother has so evidently found admirable and which will thereby win him the love of a girl "just like the one who married dad." His training in self-reliance, mentioned above, and his father's loving tutelage provide the foundation for a successful identification.

A survey of the biographies of 31 engineers, mostly drawn from three sources (Goddard, 1906; Watson and Watson, 1950; and Yost, 1952), gives some support to the expectation that the father of engineers will be seen as a powerful masculine figure. In 19 out of 31 engineers, materials were available which permitted at least an inference about this characteristic of the parents. In eight instances there were specific references to the father as a strong, powerful figure and three additional instances in which this could be inferred. In four instances it is the mother's power that was depicted. In the four cases where neither a strong father nor mother was described, the father had died when the boy was young. In 14 of the cases where the father's occupation was included, all but two were highly masculine in nature. In five cases a blacksmith appears somewhere in the background, giving added significance to the title of Cooley's (1947) autobiography, Scientific Blacksmith. Other examples of aggressively masculine identities are a sur- 
geon, president of a cutlery manufacturing company, a mechanic, and a high military officer.

The tendency for engineers to have experienced a firm, demanding quality in their parents is indicated by the atmosphere of strict discipline that is conveyed by their biographers. John Erickson's mother was described as "Tall, beautiful, intellectual, and of great firmness" (Goddard, 1906, p. 87). Yost (1952) stresses the emphasis on early self-reliance in Harold Maynard's early years. John R. Suman grew up "in a home where he learned to work for what he wanted" (Yost, 1952, p. 124). Cooley (1947) in his autobiography says, ". . . in the house one learned that the word of a father or mother was law; there was no back talk. (p. 24) ... it was not enough to understand right from wrong; it was necessary to do right or suffer the consequences" (p. 3). His mother "was expert at many things including use of the back of a hairbrush" and his father, too, "used the switch thoroughly" (p. 1).

\section{INTEREST IN AUGMENTING PHYSICAL POWER}

The simplest, most direct way to account for the engineer's preoccupation with augmenting man's physical powers is to say that he must have been of slight physique or have had to overcome some debilitating illness. To account for the fact that in much of engineering there is a substrate of actual vigor and aggressive action, we must assume that whatever physical deficiencies the engineer suffered must have been overcome early in order for him to be successful in his role. Further, Begelman (1951) demonstrated that as an older adolescent the engineer could not be described as markedly deficient in physical power. More certain is the inference that, like all small boys, the engineer felt physically deficient when comparing himself with a grown man (his father). When, as has been suggested earlier, that grown man was himself a psychologically strong masculine figure who treated the boy sternly, some of the conditions for being preoccupied with one's own physical weakness are satisfied. So here again we must appeal to the process of re- solving the oedipal conflict as the developmental source and suggest that the aforementioned strong characteristics of the father along with sufficient affection and companionship made it possible for the boy to set for himself the goal of capturing some of his father's strength by making use of his special intellectual abilities to augment his efforts to develop his physical capacities via tools. Part of this inference is documented by the fact that for 18 of our 31 engineers specific mention is made of a very early interest in tools and mechanical (or electrical) devices.

\section{CHOICE OF THE "ENGINEERING METHOD"}

Much of the basis for understanding the engineer's attachment to orderly, dispassionate, and planful ways of coping with life is provided in the kinds of developmental experiences that have already been postulated. In accounting for his investment with products and the practical, we suggested that the engineer's parents would tend to be on the undemonstrative side. We have also described them as strong, firm parents, perhaps on the severe side. They make demands for self-reliance and achievement. Thus the child is placed under threat and is taught by his parent's example to react with little display of emotion. You might expect that one or both parents would have been very orderly persons. Since such traits are thought to owe their origin to the period of toilet training, one might expect the engineer's mother to be characterized as an orderly housekeeper who kept her house (and her children) neat and clean.

\section{VOCATIONAL CONFLICT IN THE ENGINEER}

Our analysis of the personality needs which engineering satisfies, and the pivotal experiences on which the development of an engineer turns, should give us some basis for a better understanding of the sources of the difficulties of vocational development that would give rise to conflicts and indecision at various choice points. We believe that many of the difficulties displayed in the area of educational and vocational choices can be ascribed to the vicissitudes of personality development of which vocational 
development is one reflection. We are not speaking here of the more marked anomalies of development that give rise to the severe inner conflicts or the self-defeating symptoms of the clinical case. Such persons will, of course, exhibit characteristic problems in their educational and vocational life, but the widespread character of their many personality difficulties will help to underline the significance of their difficulties in the vocational aspects of their lives. Our emphasis is upon the course of development of the adolescent who is managing to function adequately even though not without psychic pain. He is part of that large group whose development might be considerably enhanced by judicious and limited psychological help as they pass through their "adolescent crisis," but who will manage to reach maturity and live through their lives on an acceptable, if lower level, without that help.

One of the likely focuses of difficulty for the prospective engineer can lie in the incompleteness of his identification with his father. An overly stern father, one who is unable to balance his demanding and controlling ways with a warm friendliness and a willingness to share his interests and enthusiasms with his son, can induce a strong but highly fearful identification. Such a son will fear the task of following in his father's footsteps, yet be reluctant to reject his demand that his son emulate him. Deans of engineering schools are familiar with the timid, reluctant boys dragged into their offices by domineering, unrealistic fathers. Sometimes anger and rebellion, covertly expressed, is the son's response. He may be capable of functioning in engineering and under freer circumstances would have chosen it on his own accord, but finds that the only way to express his opposition is by failing out of the training program.

The sharply delineated masculinity of the engineering role makes its choice a prime defense for the youngster who is experiencing anxiety about his masculinity. He seeks to down his own doubts and to convince others by choosing this obviously masculine vocation. Such a youngster will cling to this choice in the face of contradictory realities of the natural bent of his mind and other equally well-established promptings of his feelings and interests. Often his choice will fly in the face of well-expressed interests and activities that point to voca tions far removed from the sphere of the engineer.

Finally, there are those young men whose development has not pushed them irrevocably into the sphere of the impersonal. These youngsters, while fearing it and being uncertain of their potential for success, long for greater experiences of interpersonal intimacy than can be obtained in even the most social forms of engineering activities. There are those among them who, with only relatively brief help, may succeed in overcoming the inner obstacles toward freer and more satisfying interpersonal relationships. Others will use the same amount of help to find some satisfying balance between a vocational life of engineering and a social and personal life which adds some of the necessary nutriments of intimacy and emotional exchange.

\section{REFERENCES}

ANGel, J. L. Careers in engineering. New York: World Trade Academy Press, 1953.

BegelmaN, J. Relation of body build, physical performance, intelligence, and recreational interests to occupational choice. Unpublished Ph.D. thesis. Ann Arbor: Univ. of Michigan, 1951.

BLUM, L. P. A comparative study of students preparing for five selected professions including teaching. J. exp. Educ., 1947, 16, 31-65.

Bordin, E. S., NAchmanN, Barbara, \& SEgal, S. J. An articulated framework for vocational development. J. counsel. Psychol., 1963, 10, 107-118.

Cooley, M. E. Scientific blacksmith. Ann Arbor: Univ. of Michigan Press, 1947.

DE LESSEPS, F. Recollections of forty years. Iondon: Chapman and Hall, 1887.

DRAYER, C. E., \& NeWELl, F. H. (Eds.) Engineering as a career: $A$ series of papers by eminent engineers. New York: D. Van Nostrand, 1916.

Engineering as a career. New York: Engineers Council, 1942.

Galinsky, M. D. Personality development and vocational choice of clinical psychologists and physicists. J. counsel. Psychol., 1962, 9, 299-305.

GodDard, D. Eminent engineers. New York: The Derry Collard Co., 1906.

Guides to planning an education. Ann Arbor: Univ, of Michigan Press, 1961.

Harrison, R., Tomblen, D. T., \& Jackson, T. A. Profile of the mechanical engineer III. Personality. Personnel Psychol., 1955, 8, 469-490.

Harrower, G. J., \& Cox, K. J. The results obtained 
from a number of occupational groupings on the professional level with the Rorschach Group method. Bull. Canad. Psychol. Assn., 1942, 2, 31-33.

Kulrerg, G. E., \& Owens, W. A. Some life history antecedents of engineering interests. $J$. educ. Psychol., 1960, 51, 26_31.

MAXWELL, W. J. Letters of an engineer. London: Marcus Ward and Co., Oriel House, Farrington Street, E. C. and Royal Ulster Works, Belfast, 1886.

MrLs, J. The engineer in society. New York: D. Van Nostrand, 1946.

MOORE, H. B., \& LEvy, S. I. Artful contrivers: A study of engineers. Personnel, 1951, 28, 148 153.

Mosier, M. F., \& Kuder, G. F. Personal preference differences among occupational groups. $J$. appl. Psychol., 1949, 33, 231-239.

Nachmann, Barbara. Childhood experiences and vocational choice in law, dentistry, and social work. J. counsel. Psychol., 1960, 7, 243-250.

RIDcway, R. Robert Ridgway. New York. Privately published, 1940 .

RoE, A. The psychology of occupations. New York: Wiley, 1956.

SEgal, S. J. A psychoanalytic analysis of personality factors in vocational choice. J. counsel. Psychol., 1961, 8, 202-210.

Stevenson, R. L. Records of a family of engineers. London: Chatto and Windus, 1912.

StEWART, L. O. A career in engineering. Occupational Monograph, No. 30. Chicago: Science Research Associates, 1942.

Thorndike, R. L., \& HAGEN, E. 10,000 careers. New York: Wiley, 1959.

Watson, S. R., \& Watson, E. Famous engineers. New York: Dodd, Mead and Co., 1950.

Yost, E. Modern American engineers, New York: J. B. Lippincott, 1952.

\section{NEW SERVICE RECRUITS EDUCATORS FOR OVERSEAS}

Overseas Educational Service is a new organization recently formed under the joint sponsorship of the National Academy of Sciences, the American Council on Education, and Education and World Affairs. OES was formed to help the governments and institutions of developing nations identify available academic and administrative personnel to aid in the development of new higher education institutions abroad and to provide opportunities for American educators to gain experience in the cultures and traditions of Asian, African, and Latin American countries.

Although OES plans to do some recruiting of academic personnel on its own, it will supplement the efforts of other agencies, both public and private, that are engaged in recruiting American personnel for the developing areas. As it accumulates information, OES expects to serve as a central clearinghouse both for American agencies and for representatives of host institutions in the new nations.

John Scott Everton, former U. S. ambassador to Burma, is executive director of the new organization. Inquiries about OES should be addressed to Overseas Educational Service, 522 Fifth Avenue, New York 10036 . 